\title{
Indikator Kinerja dan Peran Stakeholder dalam Pengelolaan Daerah Aliran
}

\section{Sungai (DAS) Lisu}

\author{
Yulsan Demma Semu1, Usman Arsyad², Anwar Umar² \\ 1Program Studi Ilmu Kehutanan, Pascasarjana Fakultas Kehutanan Universitas Hasanuddin, \\ Makassar \\ 2Fakultas Kehutanan Universitas Hasanuddin, Makassar \\ *E-mail: yulsan1990@gmail.com
}

\begin{abstract}
Various community activities that have occurred in the Lisu Watershed have seemed irregular and unregulated. This can be seen in the management of the Lisu watershed, which has not been used thoroughly from policy, implementation to evaluation and monitoring in the management of the Lisu watershed. The emergence of various problems and conflicts between various interests in its management. So the purpose of this study is how to analyze collaboration and stakeholder synergy in natural resource management in the Lisu Watershed. This research was conducted with descriptive exploratory analysis method on the activities of stakeholders who will collaborate in the management of the Lisu watershed, and how to identify performance indicators. The results obtained in this study are the overlapping functions, duties and responsibilities and authority in the management of the Lisu watershed. Related stakeholders have not been based on effectiveness, namely the goals and objectives in improving the quality of the Lisu watershed, causing a conflict of interest and lack of coordination. Another obstacle faced by stakeholders in collaborating and synergy is the disagreement of some stakeholders in integrating watershed management whose management is from upstream, middle and downstream of the Lisu watershed. The recovery policy in the Lisu Watershed is needed in realizing and building integrated watershed management patterns in collaboration and stakeholder synergy. As well as the need for a change of management paradigm as well as institutional strengthening in the management of the Lisu Watershed.
\end{abstract}

Keywords: Collaboration, institutional, policy, synergies, watershed

DOI: http://dx.doi.org/10.24259/jhm.v10i2.4796

\section{PENDAHULUAN}

Daerah Aliran Sungai (DAS) Lisu merupakan salah satu DAS yang sangat berperan penting dan mempunyai posisi yang strategis dimana penting dalam pembangunan di Kabupaten Barru. Daerah Aliran Sungai (DAS) Lisu termasuk daerah pertanian yang cukup potensial. Bebagai jenis komoditi pertanian, perkebunan, peternakan, perikanan yang bernilai ekonomi diusahakan di DAS Lisu dan sangat sesuai dengan kondisi lingkungan tempat tumbuh didaerah ini. Kondisi tersebut menyebabkan daerah ini banyak diminati oleh masyarakat baik Pemerintah maupun masyarakat dunia usaha dari luar. Sejalan dengan perkembangan berbagai usaha tani di daerah ini berbagai kegiatan bukan pertanian juga berkembang seperti industri pengolah hasil pertanian, perdagangan dan kegiatan-kegiatan lainnya.

Perkembangan berbagai kegiatan di DAS Lisu selama ini terkesan tidak teratur dan tidak diatur dimana pengelolaan DAS Lisu belum digunakan secara menyeluruh dari kebijakan, pelaksanaan sampai evaluasi dan monitoring dalam pengeloaan DAS Lisu. Hal ini dapat dilihat pada munculnya berbagai masalah dan konflik antara berbagai kepentingan di wilayah DAS Lisu. Konflik penggunaaan lahan, status pemilikan lahan, penggunaan air, pelestarian sumber air, perambahan di kawasan hutan dan penebangan ilegal merupakan masalah-masalah yang muncul hampir setiap saat di daerah ini. Masalah-masalah tersebut di atas cenderung semakin meningkat dan telah memberikan dampak yang luas baik terhadap lingkungan sosial budaya, sosial 
ekonomi maupun terhadap lingkungan biofisik. Apabila hal ini berlangsung terus, maka pada akhirnya akan berakibat pada penurunan produksi dan pendapatan petani, serta pendangkalan di DAS Lisu.

Dalam hal ini kolaborasi dan slnergitas stakeholder sangat dibutuhkan dalam pengelolaan Daerah Aliran Sungai (DAS) Lisu untuk tetap menjaga formalisasi dan implementasi kegiatan atau program yang bersifat manipulasi sumberdaya alam dan manusia yang terdapat di daerah aliran sungai untuk memperoleh manfaat produksi dan jasa tanpa menyebabkan terjadinya kerusakan sumberdaya air dan tanah. Asdak (2004), mengemukakan sebagai pengelolaan dan alokasi sumberdaya alam di daerah aliran sungai termasuk pencegahan banjir dan erosi, serta perlindungan nilai keindahan yang berkaitan dengan sumberdaya alam. Termasuk dalam pengelolaan DAS adalah identifikasi keterkaitan antara tataguna lahan, tanah dan air, dan keterkaitan antara daerah hulu dan hilir suatu DAS. Pengelolaan DAS perlu mempertimbangkan aspek-aspek sosial, ekonomi, budaya dan kelembagaan yang beroperasi di dalam dan di luar Daerah Aliran Sungai yang bersangkutan.

Ekosistem harus dilihat secara holistik, yaitu dengan cara mengidentifikasi komponen-komponen kunci penyusun ekosistem serta menelaah interaksi antar komponen-komponen tersebut. Pendekatan holistik dilakukan agar pemanfaatan dan konservasi sumber daya alam dapat dilakukan secara efisien dan efektif, yang merupakan syarat bagi terwujudnya pemanfaatan sumberdaya alam untuk pembangunan yang berkelanjutan (Asdak, 2004). Pengelolaan DAS merupakan salah satu kewenangan pemerintah yang dapat didesentralisasikan berdasarkan authority maupun urusan (fungsi). Bentuknya sendiri dapat mengacu kepada model pembagian Chema, et. al dalam Raharja (2009) yaitu dekonsentrasi, delegasi kepada organisasi parastral atau semi-otonom, devolusi, privatisasi atau transfer urusan dari pemerintah kepada lembaga non pemerintah. Kinerja antar kelompok yang sukses merupakan sebuah fungsi dari sejumlah faktor. Konsep lebih luas (umbrella concept) yang mengasampingkan faktor-faktor ini adalah koordinasi tiap faktor berikut ini dapat mempengaruhi upaya koordinasi.

Untuk tercapainya pembangunan DAS yang berkelanjutan kegiatan pembangunan ekonomi dan perlindungan lingkungan harus diselaraskan. Dalam hal ini diperlukan penyatuan kedua sisi pandang tersebut secara realistis melalui penyesuaian kegiatan pengelolaan DAS dan konservasi daerah hulu ke dalam kenyataan-kenyataan ekonomi dan sosial. Maka dari itu perlu diketahui masing-masing peran para pihak yang akan berkolaborasi dalam pengelolaan DAS Lisu, serta bagaimana mengidentifikasi indikator kinerjanya.

\section{METODE PENELITIAN}

\subsection{Waktu dan Tempat}

Penelitian ini dilaksanakan dari bulan Februari sampai Maret 2018. Penelitian ini dilaksanakan di DAS Lisu Sulawesi Selatan.

\subsection{Teknik Pengumpulan dan Jenis Data}

Pengumpulan data dilakukan untuk memperoleh informasi yang dibutuhkan dalam rangka mencapai tujuan penelitian ini, yakni di bagi atas dua bagian yaitu data primer dan data sekunder. Data primer dikumpulkan dengan menggunakan metode survei, yaitu metode yang digunakan untuk meminta tanggapan responden mengenai pengelolaan DAS Lisu dan merekam kondisi di lokasi penelitian DAS Lisu. Sedangkan data sekunder dilakukan melalui studi pustaka dan data instansi terkait.

Teknik pengumpulan dengan mengumpulkan infomasi kinerja pengelolaan DAS meliputi: (1) Penentuan kebijakan, (2) Penentuan sasaran dan tujuan kegiatan, (3) Rencana kegiatan, (4) Implementasi kegiatan, dan (5) Evaluasi dan monitoring.

\section{a. Wawancara Individual (Individual interview)}

Metode ini dilakukan dengan wawancara indept interview dan wawancara bertipe open-ended dengan menggunakan pedoman wawancara dan kuesioner. Jenis data yang dikumpulkan adalah: (a) mengidentifikasi kelembagaan, (b) keterkaitan antara kelembagaan dalam pengelolaan DAS Lisu. 
b. Observasi - Pengikutsertaan (Participant observation)

Metode ini dilakukan dengan pengamatan langsung dilokasi penelitian tentang tindakan kolaborasi dan sinergitas Pemerintahan dalam pengelolaan DAS Lisu.

c. Studi Literatur

Studi literatur dimaksudkan untuk memperoleh informasi pendukung seperti dassar huku Pengelolaan Daerah Aliran sungai, kondisi biofisik daerah aliran sungai, data statistik, rencana pengelolaan daerah aliran sungai, laporan hasil-hasil penelitian, peta kerja dana peta citra. Data-data tersebut diperoleh dari lembaga pemerintah dan instansi-instansi terkait.

\section{d. Dokumentasi}

Dokumentasi adalah pengambilan gambar pada berbagai objek guna memberikan gambaran yang lebih jelas tentang topik yang dibahas. Data yang diperlukan dalam penelitian ini adalah data primer dan data sekunder, data primer adalah data yang diperoleh melaui wawancara dengaan responden melalui observasi. Data yang dikumpulkan meliputi:

1. Identitas responden (nama, umur, tingkat Pendidikan, jabatan di instansi yang terkait/di tataran strukrur desa).

2. Program dan kebijakan dalam membangun pengelolaan DAS.

3. Peranan struktur sosial.

Sedangkan data sekunder adalah data yang diperoleh dari hasil penelitian, literature, karya ilmiah, serta data dari stakeholder dan informasi lainnya berkaitan dengan penelitian melalui studi literatur.

\subsection{Analisis Data}

Berdasarkan data yang didapatkan terlebih dahulu dilakukan analisis secra deskriptif kualitatif terhadap kegiatan stakeholder dalam melakukan pengelolaan DAS Lisu. Analisis disederhanakan lewat tabel dan dijabarkan dengan penjelesan yang relevan sehingga mudah dapat diinterpretasi dengan baik. Hal ini dilakukan untuk mendapatkan perbandingan antara stakeholder berkolaborasi dan sinergitas dalam pengelolaan DAS Lisu.

\section{HASIL DAN PEMBAHASAN}

\subsection{Indikator Kinerja Stakeholder dalam Pengelolaan di DAS Lisu}

Peranan stakeholder dalam pengelolaan Daerah Aliran Sungai adalah menentukan kebijakan, penentuan sasaran dan tujuan kegiatan, rencana kegiatan, implementasi program yang telah direncanakan serta evaluasi dan monitoring kegiatan. Peranan stakeholder juga berkolaborasi dan bersinergi dalam pengelolaan Daerah Aliran Sungai untuk mendapatkan korelasi yang baik. Stakeholder memiliki wewenang dan tanggung jawab dalam hal pengelolaan Sumber Daya Alam sekitar DAS Lisu. Stakeholder diharapakan dapat memberikan kontribusi langsung maupun tidak langsung dalam pengelolaan DAS Lisu. Adapun 5 indikator ukuran diperoleh berdasarkan hasil wawancara dan penilaian skor kinerja kegiatan yang dilakukan berbagai stekholder ialah sebagai berikut:

\section{a. Penentuan Kebijakan}

Peran Stakeholder memliki kebijakan dalam penentuan sasaran kegiatan di DAS Lisu mulai dari Peraturan Menteri, Peraturan Daerah Provinsi Kabupaten serta Peraturan Daerah Kabupaten Barru. Kebijakan inilah yang sebagai penentu keberlanjutan kriteria dalam pengelolaan DAS Lisu. 
b. Sasaran dan Tujuan Kegiatan

Stakeholder memiliki masing-masing penentuan sassaran dan tujuan kegiatan di DAS Lisu yang kadang bertolak belakang. Contoh kasus: Dinas Pertanian yang membulka lahan pertanian dan perkebunan di wilayah hulu yang seharusnya wilayah hulu bagian dari wilayah Kehutanan.

\section{c. Perencanaan Kegiatan}

Dalam perencanaan kegiatan Pengelolaan DAS Lisu tidak semua stakeholder terlibat dalam perencanaan kegiatan. BPDASHL dan Forum DAS serta masyarakat DAS Lisu mempunyai perencanaan kegiatan pembangunan KTA di Desa Pujananting dan Desa Pallakka serta Dinas Pertanian memilki perencanaan kegiatan dalam "Mensejahterahkan Masyarakat Tani di DAS Lisu". Sedangkan Dinas Kehutanan Provinsi Sulawesi Selatan belum memliki perencanaan Kegiatan disebabkan adanya peralihan wewenang dari Dinas Kehutanan Kabupaten ke Dinas Kehutanan Provinsi Sulawesi Selatan, Dinas Badan Pembangunan Daerah Kabupaten Barru dan Dinas Pekerja Umum Kabupaten Barru juga belum memliki perencanaan Kegiatan dengan alasan belum terealisasikan permohonan perencanaan kegiatan.

\section{d. Implementasi Kegiatan}

Implementasi kegiatan BPDASHL Jeneberang dan Saddang dalam mengimplementasikan atau merealisasikan kegiatan dengan baik dengan Forum DAS dan masyarakat DAS Lisu dalam pembangunan KTA (gully flug dan sumur resapan) di desa Pallakka dan Desa Pujananting tahun 2017. Dinas Pertanian Kabupaten Barru juga mengimplementasikan kegiatan sesuai dengan rencana kegiatan dalam "Mensejahterakan Masyarakat Tani DAS Lisu" dalam pengembangan pertanian, perkebunan dan peternakan. Dinas Pertanian Kabupaten Barru merealisasikan dalam bentuk bantuan pengadaan bibit padi unggul, tanaman perkebunan (kopi rabusta, pala, tembakau, jambu mentah dan kelapa di daerah pesisiran di Desa Pujananting serta memberi bantuan masyarakat dalam berternak serta melakukan penanaman rumput gajah di sekitar bantaran sungai untuk sebagai bahan pakan ternak.

Dalam bentuk kerjasama BPDASHL Jeneberang dan Saddang dengan Forum DAS yang mengikutsertakan masyarakat dalam kegiatan pembangunan KTA (gully flug dan sumur resapan) bisa dikatakan berkolaborasi dan bersinergitas dalam Pengelolaan DAS Lisu. Stakeholder lainnya belum melakukan kolaborasi dan sinergitas dalam pengelolaan DAS Lisu karena memiliki kebijakan, kegiatan serta tujuan yag kadang bertolak belakang. Dinas Pertanian Kabupaten Barru membuka lahan pertanian di bantaran sungai serta wilayah hulu yangs seharusnya menjadi wilayah kehutanan yang dijaga sumber daya alamnya dijadikan lahan perkebunan jangka pendek (jagung) di Desa Jangan-Jangan. Dinas Pekerjaan Umum Kabupaten Barru belum melakukan tindakan pembangunan infrastruktur dengan baik di wilayah DAS Lisu.

\section{e. Monitoring dan Evaluasi Kegiatan}

Forum DAS dan masyarakat melakukan monitoring dan evaluasi kegiatan pembangunan KTA di DAS Lisu dengan BPDASHL Jeneberang dan Saddang. Untuk melihat kinerja pembangunan KTA. Sedangkan Dinas Pertanian Kabupaten Barru melakukan kegiatan "MUSRENBANGDES" untuk sebagai pengevaluasian para petani dan juga menampung keluhan masyarakat tani di DAS Lisu hal ini dilakukan dalam tiap tahunnya.

Hasil dari penelian indikator kinerja stakeholder dalam pengelolaan DAS Lisu dapat diliat dari skor lima (5) indikator dalam pengelolaan DAS yaitu; penentuan kebijakan, penentuan sasaran dan tujuan kegiatan, perencanaan kegiatan, implementasi kegiatan serta monitoring dan evaluasi kegiatan di DAS Lisu. Dalam pengelolaan DAS Lisu haru adanya keterpaduan pengelolaan dari hulu, tengah dan hilir DAS tetapi stakeholder belum berkolaborasi dan bersinergitas dalam pengelolaan DAS Lisu karena memiliki kepentingan sendiri yang saling bertolak belakang

Kolaborasi stakeholder belum terealisasikan dengan baik mulai dari penentuan kebijakan, penentuan sasaran dan tujuan kegiatan, perencanaan kegiatan serta monitoring dan evaluasi kegiatan tetapi, dalam bersinergitas belum cukup bagus karena stakeholder memiliki tujuan dan kegiatan yang kadang kalah bertolak 
belakang serta pengelolaan DAS Lisu mulai dari wilayah hulu, tengah dan hilir belum terigentrasi dan bersinerginya stakeholder dalam pengelolaan sumber daya alam dan lingkungan DAS Lisu.

\subsection{Peranan Stakeholder dalam Pengelolaan DAS Lisu}

Bentuk keterpaduan dalam pengelolaan DAS yang diambil mulai dari penentuan kebijakan, penentuan sasaran dan tujuan kegiatan, rencana kegiatan, implementasi kegiatan dan evaluasi serta monitoring kegiatan stakeholder. Adapun bentuk-bentuk kegiatan/peran stakeholder dalam pengelolaan DAS Lisu:

\section{a. BPDAS HL Jeneberang Saddang Sulawesi Selatan}

BPDASHL Jeneberang Saddang Provinsi Sulawesi Selatan memiliki kebijakan mengenai pengelolaan DAS, DAS Lisu hanya dalam ruang lingkup Kabupaten Barru, sedangkan BPDASHL Jeneberang Saddang Provinsi Sulawesi Selatan sendiri memiliki (dua) 2 DAS prioritas yaitu DAS Saddang dan DAS Jeneberang yang dikelola secara menyeluruh oleh BPDASHL Jenebarang Saddang. Berdasarkan Peraturan Pemerintah Nomor 37 Tahun 2012 tentang Pengelolaan DAS maka DAS yang termasuk dalam Prioritas Nasional tersebut merupakan DAS dengan Klasifikasi "DAS yang dipulihkan daya dukungnya". DAS mempunyai peran yang sangat besar sebagai sistem perlindungan dan penyangga kehidupan, oleh karena itu keberadaannya perlu dikelola dengan baik, sehingga dapat berfungsi secara lestari. Bentuk kinerja BPDAS HL Jeneberang dan Saddang dalam pengelolaan DAS Lisu ataupun peran bisa diliat dalam Tabel 1 .

Tabel 1. Kinerja BPDASHL Jeneberang Saddang dalam Pengelolaan DAS Lisu.

\begin{tabular}{cccc}
\hline No & Kriteria & Indikator & Ket \\
\cline { 2 - 4 } 1 & Penentuan Kebijakan & $\begin{array}{c}\text { Tidak adanya kebijakan } \\
\text { pengelolaan DAS Lisu }\end{array}$ & PP no. 37 tahun 2012 \\
\cline { 2 - 4 } 2 & $\begin{array}{c}\text { Penentuan Sasaran } \\
\text { dan Tujuan kegiatan }\end{array}$ & $\begin{array}{c}\text { Adanya penentuan sasaran dan } \\
\text { tujuan kegiatana }\end{array}$ & $\begin{array}{c}\text { Desa Mattappawalle, Kecamatan } \\
\text { Pujananting dan Desa Palakka, } \\
\text { Kecamatan Barru }\end{array}$ \\
\cline { 2 - 4 } 3 & Rencana Kegiatan & Rencana Kegiatan & Pembangunan KTA \\
\cline { 2 - 4 } 4 & Implementasi Kegiatan & $\begin{array}{c}\text { Terimplementasinya kegiatan di } \\
\text { DAS Lisu }\end{array}$ & Pembangunan KTA \\
\cline { 2 - 4 } 5 & Evaluasi dan Monitoring & $\begin{array}{c}\text { Adanya evaluasi dan monitoring } \\
\text { kegiatan di DAS Lisu }\end{array}$ & terealisasinya evaluasi dan monitoring \\
\hline
\end{tabular}

BPDASHL Jeneberang Saddang merupakan salah satu UPT Direktorat Jenderal Pengendalian DAS dan Hutan Lindung KemenLHK yang terdapat di Provinsi Sulawesi Selatan dengan luas wilayah keraj \pm 4.409.990.35 Ha yang mencangkup seluruh Kabupaten/kota Sulawesi Selatan. Pada awalnya BPDASHL Jeneberang Saddang merupakan 2 UPT yaitu BPDAS Jeneberang Walanae dan BPDAS Saddang. Tetapi sejak tahun 2016 digabung menjadi 1 UPT.

Di wilayah kinerja untuk DAS Lisu BPDAS Jeneberang Saddang provinsi Sulawesi Selatan sendiri tidak mempunyai andil dalam menentukan kebijakan serta pengelolaan DAS Lisu itu sendiri. Sehingga BPDAS HL Jeneberang Saddang tidak berperan penting dalam kolaborasi dan sinergitas stakeholder dalam pengelolaan DAS Lisu.

\section{b. Dinas Kehutanan Provinsi Sulawesi Selatan}

Dinas Kehutanan Provinsi memiliki kebijakan tentang Pengelolaan Daerah Aliran Sungai yang dilihat dari Peraturan Daerah Provinsi Sulawesi Selatan Nomor 10 Tahun 2015 dan memiliki sasaran dan tujuan kegiatan sasaran, tetapi belum menentukan rencana kegiatan, implementasi kegiatan dan evaluasi dmonitoring. Menurut Ansar, hal ini terjadi dikarenakan adanya peralihan wewenang dari Dinas Kehutanan Kabupaten ke Dinas Kehutanan Provinsi berdasarkan Undang-Undang 23 Tahun 2014. 
Dinas Kehutanan Kabupaten Barru pada saat itu tidak memiliki kebijakan khusus mengenai pengelolaan DAS Lisu dan dari tahun 2007 sampai tahun 2018, \pm 11 tahun tidak ada perlakuan/pengelolaan lagi di DAS Lisu karena, kegiatan berfokus ke DAS Saddang. Dinas Kehutanan Kabupaten Barru belum melakukan tindakan kolaborasi dan sinergitas secara langsung dalam pengelolaan DAS Lisu. Bentuk kinerja Dinas Kehutanan Provinsi bisa diliat dalam Tabel 2.

Tabel 2. Kinerja Dishut Provinsi Sulawesi Selatan dalam pengelolaan DAS Lisu.

\begin{tabular}{llll}
\hline No & \multicolumn{1}{c}{ Kriteria } & \multicolumn{1}{c}{ Indikator } & \multicolumn{1}{c}{ Ket } \\
\hline 1 & $\begin{array}{l}\text { Penentuan } \\
\text { Kebijakan }\end{array}$ & $\begin{array}{l}\text { Adanya kebijakan pengelolaan DAS } \\
\text { tetapi tidak terlaksana }\end{array}$ & $\begin{array}{l}\text { Peraturan Daerah Prov. Sul-Sel no. 10 thn } \\
2015 \text { tentang Pengelolaan DAS tetapi } \\
\text { belum terlaksana }\end{array}$ \\
\hline \multirow{2}{*}{$\begin{array}{l}\text { Penentuan } \\
\text { sasaran dan } \\
\text { tujuan kegiatan }\end{array}$} & $\begin{array}{l}\text { Adanya penentuan sasaran dan } \\
\text { tujuan kegiatan }\end{array}$ & $\begin{array}{l}\text { Peraturan Daerah Prov. Sul-Sel no. 10 thn } \\
\text { 2015 tentang Pengelolaan DAS BAB II } \\
\text { Bagian Ketiga Tujuan Pasal 4 }\end{array}$ \\
\hline
\end{tabular}

3 Rencana Kegiatan Belum adanya rencana kegiatan

Belum ada rencana kegiatan di DAS Lisu dikarenakan adanya peralihan wewenang dari Dinas Kehutanan Kabupaten Ke Dinas Provinsi berdasarkan UU 232014

Belum ada rencana kegiatan di DAS Lisu dikarenakan adanya peralihan wewenang dari Dinas Kehutanan Kabupaten Ke Dinas Provinsi berdasarkan UU 232014 di DAS Lisu

Belum ada rencana kegiatan di DAS Lisu

5 Evaluasi da

Belum adanya evaluasi dan dikarenakan berdasarkan UU 232014

Bentuk-bentuk Kinerja Dinas Kehutan Provinsi Sulawesi Selatan belum terealisasikan dengan baik karena adanya peralihan wewenang dari Dinas Kehutanan Kabupaten digabung menjadi satu bagian yaitu Dinas Kabupaten Provinsi Sulawesi Selatan.

\section{c. Dinas Pertanian Kabupaten Barru Sulawesi Selatan}

Dinas Pertanian Kabupaten Barru sangat berperan penting dalam pengelolaan DAS Lisu. Kabupaten Barru merupakan central pertanian untuk wilayah Provinsi Sulawesi Selatan. Produksi tanaman pangan, palawija dan hortikultural di Kabupaten Barru yang sangat banyak, disamping sebagai kebutuhan pokok juga sebagai mata pencarian masyarakat sekitar DAS Lisu.

Program bersama dalam Dinas Pertanian yang termasuk Bidang Perkebunan dan Bidamg Peternakan dan melibatkan masyarakat sekitar DAS Lisu adalah kegiatan Musyawarah Perencanaan Pembangunan (MUSRENBANG) dalam tiap tahun melakukan perencanaan, penentuan dimana dilaksanakan kegiatannya serta untuk mengevaluasi dan monitoring kegiatan yang sudah terlaksana sebelumnya. Kegiatan ini sangat membantu masyarakat dimana bisa menampung segala keluhan masyarakat yang berpropesi sebagai petani, berkebun dan bertenak. 
Peran Dinas Pertanian Kabupaten Barru dalam pengelolaan DAS Lisu yang sesuai dengan fungsinya. Penghijauan di lahan pertanian serta konservasi tanah oleh masyarakat binaan Dinas Pertanian itu sendiri dan pengelolaan perkebunan secara baik yang tidak tumpang tindih dengan wilayah kehutanan.

Dinas Pertanian merupakan SKPD (Satu Kesatuan Perangkat Daerah) yang memiliki tiga (3) bagian didalamnya yaitu: (1) Bidang Pertanian, (2) Bidang Perkebunan dan (3) Bidang Peternakan. Masing-masing bidang ini memiliki cara tersendiri dalam mengimplementasikan program kerja kepada masyarakat yang tinggal di DAS Lisu.

\section{d. Bidang Pertanian}

Bidang pertanian memiliki tanggung jawab dalam suksesnya hasil panen para petani disekitar DAS Lisu itu sendiri. Dalam satu (1) tahun masyarakat para petani bisa memanen 2-3 kali. DAS Lisu sangat berperan penting dalam kelancaran hasil panen dan masyarakat sangat bergantung pada DAS Lisu itu sendiri. Bentuk kinerjanya dapat diliat dalam Tabel 3.

Tabel 3. Kinerja Bidang Pertanian, Dinas Pertanian Kab. Barru dalam pengelolaan DAS Lisu.

\begin{tabular}{clll}
\hline No & \multicolumn{1}{c}{ Kriteria } & \multicolumn{1}{c}{ Indikator } & \multicolumn{1}{c}{ Ket } \\
\hline 1 & Penentuan Kebijakan & Adanya kebijakan pengelolaan DAS & $\begin{array}{l}\text { PERDA KAB. BARR No. 5 } \\
\text { Tahun 2008 Bagian 10 Paragraf 1 }\end{array}$ \\
\hline 2 & $\begin{array}{l}\text { Penentuan sasaran dan } \\
\text { tujuan kegiatan }\end{array}$ & $\begin{array}{l}\text { Adanya penentuan sasaran dan tujuan } \\
\text { kegiatan }\end{array}$ & $\begin{array}{l}\text { Penentuan sasaran di areal } \\
\text { pertanian disekitar DAS Lisu }\end{array}$ \\
\hline 3 & Rencana Kegiatan & Adanya Rencana Kegiatan & $\begin{array}{l}\text { Adanya rencana kegiatan untuk } \\
\text { mensejahterakan masyarakat } \\
\text { petani dalam hal penyediaan bibit } \\
\text { unggul dan alat industri pertanian }\end{array}$ \\
\hline 4 & Implementasi Kegiatan & $\begin{array}{l}\text { Adanya implementasi kegiatan di DAS } \\
\text { Lisu }\end{array}$ & $\begin{array}{l}\text { Terlaksananya kegiatan } \\
\text { penyediaan bibit unggul serta } \\
\text { alat-alat industri pertanian }\end{array}$ \\
\hline 5 & Evaluasi dan Monitoring & $\begin{array}{l}\text { Adanya Evaluasi dan Monitoring } \\
\text { Kegiatan di DAS Lisu }\end{array}$ & $\begin{array}{l}\text { Tercapainya hasil panen yang } \\
\text { cukup maksimal dalam bidang } \\
\text { pertanian }\end{array}$ \\
\hline
\end{tabular}

Bidang pertanian hanya fokus di areal pertanian saja dalam hal ini sawah masyarakat sekitar DAS Lisu. Bidang Pertanian menyediakan bibit padi unggul kepada masyarakat dan sering melakukan evaluasi dan monitoring terhadap hasil panen petani saja, tetapi program yang bersentuhan dengan DAS Lisu belum terealisasikan dengan baik. Bidang Pertanian dan Pangan dalam hal keterlibatan dalam berkolaborasi dan sinergitas pengelolaan DAS Lisu belum ada sama sekali.

\section{e. Bidang Perkebunan}

Bidang Perkebunan memiliki peran dalam pengelolaan DAS Lisu yaitu terkait kebijakan mengenai pengelolaan DAS Lisu, ada kegiatan yang terimplementasikan yaitu penanaman bakau dan kelapa di bagian pesisiran itu di Desa Pujananting DAS Lisu dibagian tengah terdapat tanaman cengkeh, kakao, lada, kopi robusta, pala, tembakau, jambu menteh itu di Desa Tanete Riaja. Hal ini bisa dilihat dalam Tabel 4:

Tabel 4. Kinerja Bidang Perkebunan, Dinas Pertanian Kab. Barru dalam pengelolaan DAS Lisu

\begin{tabular}{llll}
\hline No & \multicolumn{1}{c}{ Kriteria } & \multicolumn{1}{c}{ Indikator } & \multicolumn{1}{c}{ Ket } \\
\hline 1 & \multirow{2}{*}{ Penentuan Kebijakan } & Tidak adanya kebijakan & PERDA KAB. BARRU No. 5 Tahun \\
& & pengelolaan DAS & 2008 Bagian 10 Paragraf 1 \\
\hline 2 & Penentuan sasaran dan & Adanya penentuan sasaran dan & Adanya penentuan sasaran dalam \\
\hline
\end{tabular}




\begin{tabular}{llll}
\hline & tujuan kegiatan & tujuan kegiatan & bidang perkebunan \\
\hline 3 & Rencana Kegiatan & Adanya Rencana Kegiatan & $\begin{array}{l}\text { Memberikan masyarakat bibit jangka } \\
\text { pendek yang dapat dikelolah } \\
\text { masyarakat disekitaran DAS Lisu }\end{array}$ \\
\hline 4 & Implementasi Kegiatan & $\begin{array}{l}\text { Adanya implementasi kegiatan di } \\
\text { DAS Lisu }\end{array}$ & $\begin{array}{l}\text { Terlaksananya kegiatan penanaman } \\
\text { jangka pendek oleh masyarakat }\end{array}$ \\
\hline 5 & Evaluasi dan Monitoring & $\begin{array}{l}\text { Adanya Evaluasi dan Monitoring } \\
\text { Kegiatan di DAS Lisu }\end{array}$ & $\begin{array}{l}\text { Adanya kegiatan evaluasi dan } \\
\text { monitoring dari hasil penanaman }\end{array}$ \\
\hline
\end{tabular}

Bidang Perkebunan menjalankan program penanaman bakau enam (6) bulan sehabis musim kemarau. Pihak perkebunan juga sering melakukan evaluasi dan monitoring terhadap program yang dijalankan. Mengenai kolaborasi dan sinergitas stakeholder dalam pengelolaan DAS Lisu belum ada sama sekali yang diakibatkan tiap SKPD memiliki sumber pendanaan sendiri.

\section{f. Bidang Peternakan}

Kegiatan Bidang Peternakan dalam pengelolaaan DAS Lisu memiliki kaitan dengan mensejahterakan masyarakat tani. Kegiatan penanaman rumput gajah disekitar DAS Lisu membantu pakan ternak masyarakat. Bentuk kinerja Bidang Peternakan dapat dilihat dalam Tabel 5.

Tabel 5. Kinerja Bidang Peternakan, Dinas Pertanian Kab. Barru dalam pengelolaan DAS Lisu

\begin{tabular}{clll}
\hline No & \multicolumn{1}{c}{ Kriteria } & \multicolumn{1}{c}{ Indikator } & \multicolumn{1}{c}{ Ket } \\
\hline 1 & Penentuan Kebijakan & $\begin{array}{l}\text { Tidak adanya kebijakan } \\
\text { pengelolaan DAS }\end{array}$ & $\begin{array}{l}\text { PERDA KAB. BARRU No. 5 Tahun } \\
\text { 2008 Bagian 10 Paragraf 1 }\end{array}$ \\
\hline 2 & $\begin{array}{l}\text { Penentuan sasaran dan } \\
\text { tujuan kegiatan }\end{array}$ & $\begin{array}{l}\text { Adanya penentuan sasaran dan } \\
\text { tujuan kegiatan }\end{array}$ & $\begin{array}{l}\text { Adanya sasaran kegiatan dalam } \\
\text { bidang peternakan disekitar das lisu }\end{array}$ \\
\hline 3 & Rencana Kegiatan & Adanya Rencana Kegiatan & $\begin{array}{l}\text { Adanya perencanaan kegiatan } \\
\text { disekitar DAS Lisu }\end{array}$ \\
\hline 4 & Implementasi Kegiatan & $\begin{array}{l}\text { Adanya implementasi kegiatan } \\
\text { di DAS Lisu }\end{array}$ & $\begin{array}{l}\text { Adanya penanaman rumput gajah } \\
\text { disekitar DAS Lisu sebagai bahan } \\
\text { pakan ternak dan penyediaan ternak } \\
\text { kepada masyarakat }\end{array}$ \\
\hline 5 & Evaluasi dan Monitoring & $\begin{array}{l}\text { Adanya Evaluasi dan Monitoring } \\
\text { Kegiatan di DAS Lisu }\end{array}$ & $\begin{array}{l}\text { Evaluasi dan monitoring kegiatan itu } \\
\text { terlaksan dalam bidang pengawasan } \\
\text { hasil ternak masyarakat }\end{array}$ \\
\hline
\end{tabular}

Bidang Peternakan hanya memiliki kegiatan di sekitaran DAS Lisu yaitu penanam rumput gajah sebagai pakan ternak masyarakat sekitar DAS Lisu Desa Bottilampe. Masyarakat juga dapa bantuan dari Dinas Pertanian Bidang Peternakan dan Kesehtatan Hewan berupa sapi bali (nepo) dan kambing untuk bantuan kepada masyarakat yang ingin berternak.

Sesuai keputusan dari MUSRENBANG yang diakan di tiap tahunnya masyarakat Kabupaten Barru jika ingin mendapatkan bantuan dari Dinas Pertanian masyarakat sendiri mengajukan proposal bantuan akan yang ditujukan ke Bidang Peternakan dan Kesehatan Hewan yang akan dipertimbangkan pihak Dinas Pertanian untuk merealisasikan proposal masyarakat itu sendiri.

\section{g. Dinas Pekerjaan Umum Kabupaten Barru Sulawesi Selatan}

Dinas Pekerjaan Umum Kabupaten Barru memiliki kebijakan dalam pengelolaan Daerah Aliran Sungai (DAS) dalam hal infrastruktur pembangunan jembatan, bendungan dan pengairan untuk kebutuhan para petani di Kabupaten Barru. DAS Lisu dalam laporan data base sungai dan pantai tahun 2016 Dinas Pekerjaan 
Umum belum terlaksana dengan maksimal dan hanya mengerjakan beberapa program saja di DAS Lisu yaitu pembangunan tebing dipinggiran DAS Lisu untuk menahan laju erosi.

Adapun kebijakan-kebijakan atau surat izin mengenai penambang pasir di DAS Lisu, bidang Pekerjaan Umum Kabupaten Barru mengungkapkan bahwa mereka semua memiliki izin dan yang tidak memiliki izin itu dilarang keras beraktifitas di DAS Lisu. Penambang pasir sangat merugikan masyarakat disekitar DAS Lisu, contoh kasus terjadi pendangkalan di anakan sungai Lisu yang mengakibatkan banjir dan air yang dihasilkan tidak jernih lagi.

Dinas Pekerjaan Umum Kabupaten Barru sebagai Intstitusi terdepan dalam menyelenggarakan pelaksanaan dan dimanifestasikan dalam tufokis yang yang berfokus pada tahap perencanaan teknis baik untuk perencanaan teknis baik untuk perencanaan pemeliharaan/perawatan maupun pada tahap pembangunan baru dan peningkatan. Selain itu sungai dan pantai yang sudah dibangun tetpa terpelihara dengan baik agar dapat dilalui lalu lintas dengan aman, dan sekaligus dengan tujuan mendapatkan hasil pelaksanaan sungai dan pantai dengan pembiayaan optimal dan ekonomis. Kinerja Dinas PU dalam pengelolaan DAS Lisu dapat dilihat pada Tabel 6.

Tabel 6. Kinerja Dinas PU dalam pengelolaan DAS Lisu

\begin{tabular}{clll}
\hline No & \multicolumn{1}{c}{ Kriteria } & \multicolumn{1}{c}{ Indikator } & \multicolumn{1}{c}{ Ket } \\
1 & Penentuan Kebijakan & Adanya kebijakan pengelolaan DAS & $\begin{array}{l}\text { PERDA nomor 2 tahun } \\
\text { 2010 (SPPD) }\end{array}$ \\
\hline 2 & $\begin{array}{l}\text { Penentuan sasaran dan } \\
\text { tujuan kegiatan }\end{array}$ & $\begin{array}{l}\text { Adanya penentuan sasaran dan tujuan } \\
\text { kegiatan }\end{array}$ & $\begin{array}{l}\text { Adanya sasaran dan } \\
\text { tujuan kegiatan }\end{array}$ \\
\hline 3 & Rencana Kegiatan & Adanya Rencana Kegiatan & Belum ada \\
\hline 4 & Implementasi Kegiatan & $\begin{array}{l}\text { Belum adanya implementasi kegiatan di DAS } \\
\text { Lisu }\end{array}$ & $\begin{array}{l}\text { Belum terlaksananya } \\
\text { kegiatan }\end{array}$ \\
\hline 5 & Evaluasi dan Monitoring & $\begin{array}{l}\text { Belum adanya evaluasi dan monitoring } \\
\text { kegiatan di DAS Lisu }\end{array}$ & $\begin{array}{l}\text { Evaluasi dan monitoring } \\
\text { kegiatan belum ada }\end{array}$ \\
\hline
\end{tabular}

Tabel 6 diatas menunjukkan bahwa dalam pelaksanaan tugas Dinas Pekerjaan Umum Kabupaten Barru, dijabarkan dan dimanifestasikan dalam tufokis yang berfokus pada tahap perencanaan teknis baik untuk perencanaan pemeliharaan/perawatan maupun thap pembangunan baru serta adanya peningkatan. Namun, pada realitasnya hal tersebutbelum terlaksana dengan baik.

h. Badan Perencanaan Pembangunan Daerah (BAPPEDA) Kabupaten Barru Sulawesi Selatan

Badan Perencanaan Pembangunan Daerah (BAPPEDA) Kabupaten Barru Sulawesi Selatan sangat berperan penting dalam pengelolaan Daerah Aliran Sungai (DAS) Lisu dimana penyusunan RT/RW dalam pembangunan disekitar DAS Lisu merupakan tanggung jawab BAPPEDA. Kinerja BAPPEDA Kabupaten Barru dalam rencana tata ruang wilayah (RTRW) tahun 2011-2031 dilihat dari Peraturan Daerah Kabupaten Barru Nomor 4 tahun 2012. Bahwa dalam rangka mewujudkan keterpaduan pembangunan antar sektor, daerah dan masyarakat maka rencana tata ruang wilayah merupakan investasi pembangunan yang dilaksanakan Pemerintah, masyarakat dan/atau dunia usaha. Kinerja Badan Perencanaan Pembangunan Daerah Kabupaten Barru dalam Pengelolaan DAS Lisu Bisa dilihat dalam Tabel 7.

Tabel 7. Kinerja BAPPEDA Kab. Barru dalam pengelolaan DAS Lisu

\begin{tabular}{|c|c|c|c|}
\hline No & Kriteria & Indikator & Ket \\
\hline 1 & Penentuan Kebijakan & $\begin{array}{l}\text { Adanya kebijakan pengelolaan DAS } \\
\text { tetapi belum teralisasikan }\end{array}$ & $\begin{array}{l}\text { Peraturan Daerah Kabupaten Barru } \\
\text { no } 4 \text { tahun } 20112 \text { tentan Rencana } \\
\text { Tata Ruang Wilayah Kabupaten } \\
\text { Barru Tahun 2011-2031 Bagian } 3 \\
\text { Strategi Tata Ruang Pasal } 4 \text { ayat } 3\end{array}$ \\
\hline
\end{tabular}




\begin{tabular}{clll}
\hline No & \multicolumn{1}{c}{ Kriteria } & \multicolumn{1}{c}{ Indikator } & \multicolumn{1}{c}{ Ket } \\
\hline 2 & $\begin{array}{l}\text { Penentuan sasaran dan } \\
\text { tujuan kegiatan }\end{array}$ & $\begin{array}{l}\text { Belum adanya penentuan sasaran } \\
\text { dan tujuan kegiatan }\end{array}$ & $\begin{array}{l}\text { Belum adanya tujuan dan sasaran } \\
\text { dalam rencana tata ruang wilayah } \\
\text { di das lisu }\end{array}$ \\
\hline 3 & Rencana Kegiatan & Belum adanya rencana kegiatan & Belum adanya kegiatan di das lisu \\
\hline 4 & Implementasi Kegiatan & $\begin{array}{l}\text { Belum adanya implementasi } \\
\text { kegiatan di DAS Lisu }\end{array}$ & $\begin{array}{l}\text { Belum adanya kegiatan } \\
\text { pengelolaan di DAS Lisu }\end{array}$ \\
\hline 5 & Evaluasi dan Monitoring & $\begin{array}{l}\text { Belum adanya evaluasi dan } \\
\text { monitoring kegiatan di DAS Lisu }\end{array}$ & $\begin{array}{l}\text { Belum adanya evaluasi dan } \\
\text { monitoring BAPPEDA di DAS Lisu }\end{array}$ \\
\hline
\end{tabular}

Dalam Peraturan Daerah Kabupaten Barru No.4 tahun 2012 tentang Rencana Tata Ruang Wilayah Kabupaten Barru Tahun 2011-2031 bagian keempat sistema jaringan lainnya paragraf 3 sistem jaringan sumber dayai air pasal 14 ayat 5 dan 8 dimana, ayat (5) "Prasarana sumber daya air sebagaiman dimaksud pada ayat (2) terdiri dari sistema jaringan irigasi, jaringan irigasi sekunder dan jaringan irigasi tersier yang melayani DI wilayah Kabupaten Barru" dan ayat (8)" sistem pengendalian banjir sebagaimana yang dimaksud ayat (5) dilaksanakan melalui pengendalian terhadap luapan air sungai yang terdiri dari : Sungai Barru, Sungai Kupa, Sungai Nepo, Sungai Manuba, Sungai Ceppaga, Sungai Takkalasi, Sungai Ajakkang, Sungai Palakka, Sungai Bungi, Sungai Sikapa, Sungai Mareppang, Sungai lipukasi dan Sungai Jalunru". Beberapa daerah aliran sungai (DAS) yang ada di Kabupaten Barru DAS Lisu tidak tercantum dalam perencanaan tata ruang wilayah Kabupaten Barru, padahal disisi lain DAS Lisu sudah dalam kondisi yang kritis dan berstatus "dipulihkan" dalam statu Dinas Kehutanan Provinsi Sulawesi Selatan.

\section{i. Forum DAS dan Masyarakat Sekitar DAS Lisu}

Peran Forum DAS dan Masyarakat sekitar DAS Lisu dalam Pengelolaan Daerah Aliran Sungai Lisu pada tahun 2017 berkolaborasi BPDASHL Jeneberang Saddang untuk melakukan kegitan pembangunan Konservasi Tanah dan Air di wilayah DAS Lisu. Forum DAS membantu dalam hal kegiatan monitoring dan evaluasi pembangunan Konservasi Tanah dan Air dalam hal ini penyesuaian dengan kriteria pembangunan Gully Flug dan Sumur Resapan. Peran fórum DAS dan masyarakat sekitar DAS Lisu memliki wewenang dan kewajiban yang dalam pengelolaan DAS Lisu dimana bisa membangun kolerasi untuk kolabarosi dan sinergitas dalam pengelolaan DAS Lisu. Kinerja Forum DAS \& Masyarakat sekitar DAS Lisu dalam pengelolaan DAS Lisu dapat dilihat pada Tabel 8

Tabel 8. Kinerja Forum DAS \& Masyarakat dalam pengelolaan DAS Lisu

\begin{tabular}{llll}
\hline No & \multicolumn{1}{c}{ Kriteria } & \multicolumn{1}{c}{ Indikator } & \multicolumn{1}{c}{ Ket } \\
\hline 1 & Penentuan Kebijakan & $\begin{array}{l}\text { Adanya kebijakan pengelolaan } \\
\text { DAS Lisu }\end{array}$ & $\begin{array}{l}\text { Pada PERDA Provinsi Sulawesi Selatan } \\
\text { nomor 10 tahun 2015 tentang Pengelolaan } \\
\text { Daerah Aliran Sungai }\end{array}$ \\
\hline 2 & $\begin{array}{l}\text { Penentuan Sasaran } \\
\text { dan Tujuan kegiatan }\end{array}$ & $\begin{array}{l}\text { Adanya penentuan sasaran } \\
\text { dan tujuan kegiatana }\end{array}$ & $\begin{array}{l}\text { Desa Mattappawalle, Kecamatan } \\
\text { Pujananting dan Desa Palakka, Kecamatan } \\
\text { Barru }\end{array}$ \\
\hline 3 & Rencana Kegiatan & Rencana kegiatan & Pembangunan kta \\
\hline 4 & $\begin{array}{l}\text { Implementasi } \\
\text { Kegiatan }\end{array}$ & $\begin{array}{l}\text { Terimplementasinya kegiatan } \\
\text { di DAS Lisu }\end{array}$ & Pembangunan KTA \\
\hline 5 & $\begin{array}{l}\text { Evaluasi dan } \\
\text { Monitoring }\end{array}$ & $\begin{array}{l}\text { Adanya evaluasi dan } \\
\text { monitoring kegiatan di DAS } \\
\text { Lisu }\end{array}$ & Terealisasinya evaluasi dan monitoring \\
\hline
\end{tabular}


学

Jurnal Hutan dan Masyarakat. Vol. 10(2): 257-267, Desember 2018

Diserahkan: 2018-08-02; Diterima: 2018-12-27

ISSN: 1907-5316 ISSN ONLINE: 2613-9979

Melihat dari Peraturan Daerah No 10 Tahun 2015 tentang Pengelolaan DAS sudah jelas bahwa Fórum DAS Memiliki kebijakan mengenai Pengelolaan DAS Lisu, sehingga Forum DAS memiliki kegiatan, sasaran, implementasi kegiatan serta monitoring dan evaluasi kegiatan sudah terlaksana. Secara fungsional Forum DAS berlum terealisasikan dengan baik yang belum membangun kolabrasi dan sinergitas dengan stakeholder lain untuk pengelolaan DAS Lisu.

Keterlibatan dan peran masyarakat sekitar DAS lisu sangat penting dalam pengelolaan DAS Lisu. Peran masyarakat dimana mulai dari hulu sampai hilir masyarakat harus mengetahui bentuk tindakan-tindakan disekitar DAS Lisu mulai dari pemanfaatan dan pengelolaan di sekitar DAS Lisu. Pengelolaan DAS Lisu harus memiliki kesepakatan bersama oleh setiap stakeholder. Hal ini belum kita liat di DAS Lisu dimana keterlibatan semua aspek belum berkolaborasi dan bersinergitas dalam pengelolaan DAS Lisu.

\section{KESIMPULAN}

Berdasarkan hasil penelitian, maka kesimpulan yang dapat diambil yaitu peran stakeholder dalam berkolaborasi dan sinergitas untuk pengelolaan DAS Lisu belum terealisasi dengan baik dalam menentukan kebijakan, penentuan sasaran dan tujuan kegiatan, rencana kegiatan, implementasi kegiatan serta monitoring dan evaluasi kegiatan. Stakeholder memiliki kepentingan sendiri-sendiri dengan tujuan yang kadang bertolak belakang dalam pengelolaan DAS Lisu. Adapun kendala yang dihadapi stakeholder dalam berkolaborasi dan sinergitas adalah tidak sepahamnya beberapa stakeholder dalam keterpaduan Pengelolaan DAS yang pengelolaannya dari hulu, tengah dan hilir DAS Lisu. Olehnya itu kebijakan pemulihan di DAS Lisu perlu segera direalisasikan dan membangun pola pengelolaan DAS secara terpadu dalam kolaborasi dan sinergitas stakeholder. Selain itu perlu adanya perhatian dari tiap stakeholder mengenai keadaan DAS Lisu yang menurut PERDA Provinsi Sulawesi Selatan No. 23 tahun 2015 Tentang pengelolaan Daerah Aliran Sungai di dalam daftar DAS dalam Kabupaten, DAS Lisu memiliki klasifikasi "dipulihkan" mulai dari segi pelaksanaan pengelolaan DAS, pelestarian keanekaragaman hayati, peningkatan poduktivitas lahan, restorasi ekosistem, rahabilitasi dan reklamasi lahan.

\section{DAFTAR PUSTAKA}

Asdak, Chay., 2004. Hidrologi dan Pengelolaan Daerah Aliran Sungai, Gadjah Mada University Press. Yogyakarta. Hal 539.

Dhiaulhaq, A., Wiset, K., Thaworn, R., Kane, S., \& Gritten, D. (2017). Forest, water and people: The roles and limits of mediation in transforming watershed conflict in Northern Thailand. Forest and Society, 1(2), 121-136. doi:http://dx.doi.org/10.24259/fs.v1i2.2049

Raharja, J. S., 1990. Paradigma Goevernance dalam Penerapan Manajemen Kebijakan Sektor Publik pada Pengelolaan Sungai. Universitas Padjadjaran. Hal 82-83 